\title{
Formação leitora e escritora: sujeitos que leem, contam e encantam na formação inicial e continuada.
}

\author{
Formación de lectores y escritores: sujetos que leen y narran historias em \\ la formación inicial y continuada de los docentes
}

\author{
Writing and reading educational formation: individuals who read, tell and \\ enchant in early and ongoing formation
}

\author{
Isabel C. França dos S. Rodrigues ${ }^{1}$
}

\begin{abstract}
Resumo
O trabalho tem como objetivo analisar os dados preliminares de uma pesquisa realizada em escolas públicas da região metropolitana de Belém do Pará pautada nas narrativas e nas produções (performances das práticas de leitura, escrita e de contação de histórias) dos docentes de modo a criarem condições para que também contassem outras versões das respectivas histórias no processo de ensino-aprendizagem nos Anos iniciais. O tipo de pesquisa selecionado foi a Observação participante, posto que se estabeleceu uma parceria com os sujeitos de maneira propositiva. Os principais momentos da pesquisa foram as seguintes: apresentação das diversas possibilidades de histórias a partir do que os docentes já tinham, contavam ou liam para os alunos; observação e filmagem de como eram contados, lidos, apresentados os diferentes objetos de leitura presentes nos contextos; estudos com a equipe a respeito das estratégias de trabalho envolvendo os materiais e como as performances conseguiam potencializar os temas tratados, em especial, do modo como cada profissional conduzia as atividades posteriores aos momentos de leitura e de escrita/reescrita dos textos. As equipes eram divididas sempre na dinâmica das diferentes escolas valorizando a diversidade cultura da Amazônia paraense, os materiais distribuídos pelo MEC (PNAIC) e o cotidiano das escolas. Os resultados preliminares revelam para além do que discutíamos, a articulação das atividades propostas pelo projeto e as práticas já desenvolvidas pelos professores favoreceram: ampliação do repertório das crianças, independentemente, dos níveis de apropriação do sistema de escrita alfabética; os docentes potencializaram ao longo das oficinas e minicursos suas competências leitoras e escritoras (muitos criaram histórias com seus colegas de estudo do projeto). Isso evidenciou o quanto a pesquisa pode favorecer aspectos que também dialoguem com a extensão e com o ensino em espaços formativos que se constituem nas relações com os sujeitos.
\end{abstract}

Palavras-chaves: Formação leitora e escritora. Performance. Alfabetização. Letramento.

\section{Resumen}

El objetivo del artículo es analizar los datos preliminares de una encuesta realizada en las escuelas públicas del área metropolitana de Belém do Pará, que se basa en narrativas y en producciones (actuaciones de lectura, escritura y prácticas de narración) de los docentes en el proceso de enseñanza-aprendizaje en los primeros años. El tipo de investigación seleccionada fue la observación participante. Los principales momentos de la investigación fueron los siguientes: presentación de las diversas posibilidades de las historias que los maestros ya tenían contado o leído a los estudiantes; observación y grabación de cómo se contaron y se leyeran las historias y se exhibieron los diferentes objetos de lectura presentes en los contextos; discusiones con el equipo sobre las estrategias de trabajo y los materiales y cómo las actuaciones fueron capaces de mejorar los temas desarrollados en particular, la forma en que cada profesional llevó a cabo las actividades después de los momentos de lectura y redacción/reescritura de los textos. Los equipos se dividieron siempre en las diferentes escuelas, considerando la diversidad cultural de la Amazonia, los materiales distribuidos por el MEC (PNAIC) y la rutina des escuelas. Los resultados preliminares revelan que la articulación de las actividades propuestas por el proyecto y las prácticas ya desarrolladas por los docentes fomentaban la ampliación del repertorio de los niños,

\footnotetext{
${ }^{1}$ Doutora em Educação (PPGED- UFPA); Docente do Instituto de Educação Matemática e Científica (UFPA); Belém, Pará, Brasil; janibel8@yahoo.com.br
} 
independientemente de los niveles de apropiación del sistema de escritura alfabética; los docentes fortalecieron a través de los talleres y minicursos sus habilidades de lectores y escritores (muchos han creado historias con sus colegas de estudio). Esto mostró como la investigación puede favorecer aspectos que también dialoguen con la extensión y con la enseñanza en espacios formativos que se consolidan en las relaciones con los sujetos.

Palabras-clave: formación de lectores y escritores. Rendimiento. Alfabetización.

\begin{abstract}
The objective of this study is to analyze the preliminary data of a study carried out in public schools in the metropolitan region of Belém, Pará based on narratives and productions (performances of reading, writing and storytelling practices) of teachers in order to create conditions to also tell other versions of their stories in the teaching-learning process in the early years. The type of research selected was participant observation, since a partnership with the individuals was established in a propositional way. The main moments of the research were the following: presentation of the different possibilities of stories which the teachers already had, told or read for the students; observation and filming of how they were told, read, presented the different objects of reading present in the contexts; studies with the group regarding the strategies of work involving the materials and how the performances were able to enhance the themes studied, in particular, the way in which each professional conducted the activities after the reading and writing / rewriting moments of the texts. The groups were always divided according to the different kinds of schools, valuing the cultural diversity of the Paraense Amazon, the materials distributed by the MEC (PNAIC) and the daily life at schools. The preliminary results reveal more than what we have discussed, the articulation of the activities proposed by the project and the practices already developed by the teachers helped in the expansion of the children's repertoire, regardless of the levels of appropriation of the alphabetic writing system; the teachers have enhanced their reading and writing skills throughout the workshops and mini-courses (many students have created stories with their classmates from the project). This showed how much the research can favor aspects that also interact with the extension and with the teaching in formative environments that are constituted in the relations with the individuals.
\end{abstract}

Key words: reading and writing educational formation, performance, literacy, writing and reading skills

\title{
1. Introdução
}

A temática apresentada vem de reflexões posteriores a um projeto de extensão desenvolvido em 2017 a partir um projeto PIBEX (UFPA) "Laboratório itinerante de produção textual no Ciclo de Alfabetização: desafios e proposições" que integrava um dos eixos (3) de atuação do projeto integrado Núcleo de Práticas e Linguagens Docentes. O desenvolvimento do PIBEX indicou alguns aprofundamentos de pesquisa de um dos elementos do trabalho pós-doutoral em Antropologia (PPGA-UFPA) que desenvolvemos, desde março de 2018. O objetivo é analisar como o processo de ensino-aprendizagem das crianças é ampliado a partir do repertório de historias, performance e mediação de leitura desenvolvidos pelos docentes envolvidos acompanhados pelos formadores a licenciandos nas atividades de estudo e de trabalho em turmas finais do Ciclo de Alfabetização e como o trabalho tem sido ampliado em outras comunidades da Amazônia paraense na relação com a nova versão do PIBEX (UFPA2018) intitulado "Práticas pedagógicas interdisciplinares em Alfabetização e Letramento", coordenado pela $\operatorname{Prof}^{\mathrm{a}} \mathrm{Dr}^{\mathrm{a}}$ Emília Pimenta Oliveira.

As práticas docentes têm se mostrado mais desafiadoras e a parceria com os licenciandos nos indiciaram a relevância do trabalho com a ampliação do repertório cultural, contação de histórias e desafios de escrita pelos docentes e alunos da Educação Básica. Além disso, ainda na Formação inicial, os licenciandos poderão refletir mais a respeito de conceitos tratados nos 
temas em relação com a prática a partir da pesquisa colaborativa, na qual professor e voluntário/bolsista procuram organizar o tempo, o planejamento em prol das aprendizagens dos alunos da Educação Básica. Por isso, a necessidade de se ampliar o público e as comunidades atendidas de modo a trazer para discussão também aspectos antropológicos que perpassam pelo trabalho na Formação inicial e continuada (MINASI, 2008).

\section{Formação leitora e escritora no contexto amazônico}

Para Leffa (1999), a formação do leitor-escritor precisa levar em consideração também as práticas sociais nas quais os sujeitos estão inseridos, o que se aproxima com o que Kleiman (1995) propõe. Desse modo, não se pode apenas lidar com os saberes cotidianos dos educandos, mas trabalhar a partir deles de modo a ampliar o repertório de leitura e de escrita SILVA, 2009). Esses foram alguns dos encaminhamentos que procuramos dar aos estudos mensais e propostas de atividades às turmas.

Verificou-se que os docentes que passaram a inserir mais as leituras dos materiais de Literatura Infanto juvenil disponibilizados pelo MEC e articulando com a Literatura oral Amazônica. Isso favoreceu a produção oral e textual dos alunos do Ciclo de Alfabetização e dos docentes que retextualizaram e criaram histórias envolvendo textos-base da Literatura Infanto Juvenil como "A Bela e a Fera" e "João e Maria" e das narrativas amazônicas, como por exemplo, a lenda do Boto e da Matinta Perera (RODRIGUES \& GOMES, 2017; FRANCO \& GOMES, 2017) elaboradas e dramatizadas em um dos encontros de estudo.

Catherine Walsh (2014) trabalha a memória coletiva como um dos instrumentos de para se desenvolver a pedagogia que empodere os sujeitos. Essa relação com a memória nos traz fortemente a oralidade que foi bastante invisibilizada ao longo do processo de colonização e ainda dá passos lentos em reconhecimento em detrimento da escrita. E esta virou objeto de poder. Mas, qual a importância da oralidade nos povos tradicionais que têm suas vidas bastante contempladas pautando-se na oralidade. Entretanto, foram reconhecendo a importância da escrita e saber fazer uso dela como estratégia de defesa e de negociação mediante tantos ataques aos seus direitos pelo agro e hidronegócio.

$\mathrm{Na}$ segunda versão do projeto e já inserido com atividades previstas no plano de trabalho do Pós-doutorado, temos ampliado as ações com outras escolas para que este movimento crie dinâmicas de leitura e de escrita, principalmente, nas turmas do $3^{\circ}$ ano do Ciclo de Alfabetização cujos alunos demonstrem maiores dificuldades no processo de ensinoaprendizagem. Isso se justifica pelos altos índices da retenção dos alunos neste ano/série.

\section{O trabalho com diferentes textos no Ciclo de Alfabetização}

Segundo Soares (2003), ensino de língua materna precisa levar em consideração a utilização de gêneros discursivos diversos. Eles possibilitam a construção de sentidos (SANTOS \& GOULART, 2017), pois favorecem a relação com as práticas de linguagens cotidianas e com outras esferas comunicativas. Ou seja, o repertório é fundamental na fase inicial de escolarização, principalmente, nas atividades de leitura e de escrita. A Observação participante (ANGROSINO, 2009) exerceu função importante no trabalho de 2017 por ter subsídios de cooperação entre formadores, docentes, bolsistas e voluntários. Na versão do projeto em 2018 e já na relação com o plano de trabalho do Pós-doutorado, os aspectos antropológicos serão associados de modo a compreender melhor as dinâmicas das comunidades que também serão ampliadas em termos territoriais e de públicos (quilombolas, ribeirinhos e indígenas). 
Para tanto, há a necessidade de que os alunos estejam envolvidos em práticas de leitura (VANZELLA, 20017) que possam estar ligadas à memória coletiva dos sujeitos, valorizando suas trajetórias. Isso favorece a construção de sentidos e significados do que se vive, do que são e daquilo em que acreditam, por isso, os sentidos são negociados por uma coletividade. Neste encaminhamento, valorizamos os modos de vida (WILLIAMS, 2000), a cultura das diferentes comunidades, sem desconsiderar os aspectos mais restritos ao ensino-aprendizagem da língua materna de modo a ampliar os níveis de leitura e de escrita dos alunos.

Em se tratando da Amazônia paraense, há uma ancestralidade (MATOS, 2014; MORAES, 2015) enorme por conta dos movimentos de muitos povos que por aqui se fixaram no período de colonização e pós-colonização portuguesa. Os contatos linguísticos foram intensos e muitos desses resquícios estão nos dialetos, modos de vida (lutas, datas comemorativas, religiões, dança, música, lazer, alimentação, etc.) dos povos das águas e das florestas. Muitas dessas culturas são negadas no contexto escolar que elege apenas uma que rege as ações, as atividades, as avaliações, as performances, a autoria, a vida dos educandos e docentes.

\section{Por mais espaços para performance e para o repertório de histórias no Letramento do professor}

No trabalho desenvolvido em 2017, verificou-se que a performance utilizada pelos bolsistas e voluntários ao longo das atividades de Contação de histórias (MATOS, 2014) com a turma potencializou o acervo fornecido pelo MEC e pouco explorado na escola de maneira criar uma rotina de leitura, trabalho com a oralidade e com a escrita. Tais encaminhamentos têm sido ampliados na versão 2018 do projeto e que temos acompanhado como uma das tarefas do plano de trabalho do Pós-doutorado.

O trabalho tem nos mostrado que, assim como defende Larrosa (2002), os sujeitos tendem a ser envolvidos, além dos diferentes espaços por eles ocupados, contribuindo com movimentos de empoderamento, seja na Formação inicial (licenciandos bolsistas e voluntários), seja na Formação continuada (docentes da Educação Básica) das escoas atendidas.

Desse modo, os sujeitos de ambos grupos perceberam a necessidade de trabalhar mais e melhor um dos elementos constituintes das atividades com as narrativas, a saber: a performance. Não bastava ter o repertório das histórias, os aspectos e níveis a serem trabalhados com os alunos, havia a necessidade de exercitar a performance. Os estudos mensais aprofundaram tal aspecto, pois se verificou que no Letramento docente (ROSSO et al, 2011) ela não faz parte da grade curricular, nem das estratégias o trabalho com os textos utilizados, em especial, na Formação dos docentes dos Anos Iniciais. Portanto, atribuímos ao trabalho com a performance um dos sinalizadores para que os alunos construíssem melhores sentidos e significados relação aos gêneros discursivos selecionados.

\section{Autoria na Formação docente}

Ao considerarmos que para desenvolver práticas de leitura e de escrita de maneira que os alunos construam sentidos e significados para o que leem e escrevem, temos nos dedicado a enfatizar o trabalho no aspecto da autoria dos professores. Assim como não se forma leitores sem ler, não se conta histórias sem um bom repertório, também não teremos alunos (crianças, jovens e adultos) que escrevam textos com maior autonomia e autoria.

Adotar uma postura em prol da autoria significa dizer, neste caso, que defendemos uma perspectiva enunciativo-discursiva da linguagem (BAKHTIN, 1999) de modo a favorecer que as manifestações de linguagens dos alunos sejam acolhidas, discutidas e ampliadas em sala de aula. E isso valoriza não apenas as experiências individuais deles (GOMES \& FRANCO, 
2017), mas também as experiências da coletividade a qual cada um possa pertencer, sem desconsiderar as dos professores.

Por conta disso, alguns dos desafios são procurar dialogar com as práticas de leitura e de escrita, não apenas nos contextos mais urbanos, mas procurar etnografar (GEERTZ, 1989;2001) essas práticas em quatro comunidades tradicionais na Amazônia paraense. Ampliar os públicos indo ao encontro de áreas mais insulares ou não na Amazônia pode nos mostrar que as necessidades de um trabalho em prol da performance na formação do professor dos Anos Iniciais, no que se refere às práticas de leitura e de escrita. Assim como evidenciar que há outras maneiras de se favorecer a construção de sentidos por parte dos alunos cujas realidades destoam bastante ou não dos alunos de áreas de nuances mais urbanas. Esses fatores podem sinalizar alternativas de escrita mais autônomas, tanto de alunos quanto de docentes pelo fato de que muitas destas comunidades se encontrarem em constantes lutas por reconhecimento de seus territórios e aspectos culturais (RODRIGUES, 2006; 2013).

\section{Conclusões}

A pesquisa tem nos mostrado a necessidade de ampliar os espaços e públicos de formação de modo a etnografar práticas de leitura e de escrita que retratem as culturas de comunidades tradicionais e suas relações com o contexto de delineamentos mais urbanos representados pela cidade de Belém do Pará. Isso se justifica por inúmeros motivos, principalmente, por verificamos que há nestas práticas da necessidade de um resgate da memória. E como tal, situa e impulsiona os sujeitos; cria pontes com a ancestralidade. Para os povos tradicionais a escrita assume tarefas bem específicas, já que em suas culturas a oralidade é a privilegiada. Consequências disso são os acessos, por exemplo, às instituições superiores de ensino (Graduação e Pós-Graduação) onde eles travam outras lutas, pois o acesso não garante a permanência com qualidade pela própria formatação que têm algumas universidades. Elas não seriam outras formas atualizadas de invisibilidade das trajetórias leitoras e escritoras desses sujeitos? Por isso, a necessidade de se ampliar os estudos para outros territórios e sujeitos que também passam por eventos e práticas de letramento que incidem ou são reflexos dos modos de vida desses povos.

Ainda na relação com as possibilidades de escolhas e usos da língua, podemos afirmar que construir sentido e significados perpassa por eu me dar conta de que a língua permite o diálogo com o lúdico também no processo de ensino-aprendizagem da leitura e da escrita de modo a favorecer as brincadeiras com as letras, com as palavras, com os efeitos de sentidos nas mais diferentes áreas de atuação, esferas comunicativas. Assim, as fases previstas para pesquisa poderão nos sinalizar quais as práticas de leitura e de escrita que tendem a valorizar as culturas das comunidades e que podem auxiliar no processo de ensinoaprendizagem dos alunos para além dos sentidos atribuídos pelos espaços formais de ensino.

\section{Referências bibliográficas}

ANGROSINO, M. Etnografia e Observação Participante. Porto Alegre: Artmed, 2009.

BONDIA, Jorge Larrosa. Notas sobre a experiência e o saber de experiência. Rev. Bras. Educ. [online]. 2002, n.19, pp.20-28. ISSN 1413-2478

GEERTZ, Clifford. Uma descrição densa: por uma teoria interpretativa da cultura. In: A interpretação das culturas. Rio de Janeiro: Guanabara, 1989.

Nova Luz sobre a Antropologia. Rio de Janeiro: Zahar, 2001.

GOMES, Maria Raimunda Prado. (PIBEX 2017). Os desafios e avanços no ensino da leitura e escrita a partir do trabalho com gêneros discursivos no $3^{\circ}$ ano do ciclo de alfabetização. TCC. Orientadora: Prof ${ }^{a}$ Dr $^{a}$ Isabel C. F. dos S. Rodrigues. 
FRANCO, Dayse do Socorro Assunção. VI Simpósio Artístico literário de Castanhal \& IV Colóquio de Linguística de Castanhal. Os avanços e os desafios da produção textual em turmas do ciclo de alfabetização (PIBEX- UFPA)- agosto2017.

KLEIMAN, Ângela. Os significados do letramento: uma nova perspectiva sobre a prática social da escrita. Campinas: Mercado da Letras, 1995.

LEFFA, Vilson J. O ensino de línguas estrangeiras no contexto nacional. Contexturas, APLIESP, n. 4, p. 13-24, 1999.

MATOS, Gislayne Avelar. A palavra do contador de histórias: sua dimensão educativa na contemporaneidade. 2 ed. São Paulo: Editora WMF Martins Fontes, 2014.

MINASI, Luís Fernando. Formação de professores em serviço: contradições na prática pedagógica. Porto Alegre: UFRGS, 2008. 207p. Tese (Doutorado). - Universidade Federal do Rio Grande do Sul. Doutorado em Educação.

MORAES, Taiza Mara Rauen. Literatura ouvida: a contalção de histórias como prática difusora do literário. In: MEDEIROS, Fábio Henriques. MORAES, Taiza Mara Rauen. Contação de histórias: tradição, poéticas e interfaces. São Paulo: Edições Sesc São Paulo, 2015.

RODRIGUES, Isabel Cristina França dos Santos. Professoras aposentadas em território rural/ribeirinho: identidades e práticas socioculturais. 2013. Orientador: Salomão Mufarrej Hage. Coorientadora: Nilsa Brito Ribeiro. Tese (Doutorado). Universidade Federal do Pará, Instituto de Ciências da Educação, Programa de Pós-Graduação em Educação, Belém, 2013.

Retextualização e intertextualidade em texto de alunos de $5^{\text {a }}$ série do Ensino Fundamental. Orientador: Prof. Dr. Samuel Pereira Campos. Dissertação (Mestrado em Letras) - Universidade Federal do Pará, Centro de Letras e Artes, Curso de Mestrado em Letras, Belém, 2006.

ROSSO, Ademir José. Letramento Docente: leitura e escrita do mundo e da escola 1. INTERACÇÕES. NO. 17, PP. 114-134 (2011) http://www.eses.pt/interaccoes.

SANTOS, Andréa Pessôa dos. GOULART, Cecília M. A. Estudos do discurso como referência para processos de alfabetização em perspectiva discursiva. In: GOULART, Cecília M. A et al. A Alfabetização como processo discursivo. 30 anos de A criança na fase inicial da escrita. São Paulo: Cortez, 2017.

SILVA, Damares Souza. Avaliação do repertório de leitura de alunos de $3^{\text {a }}$ Série do ensino fundamental - uma análise das dificuldades apresentadas. Mestrado em Educação: Psicologia da Educação. Dissertação. Pontifícia Universidade Católica de São Paulo. PUC - SP. Orientadora: Dra. Melania Moroz. São Paulo, 2009.

SOARES, Magda, Letramento e alfabetização: as muitas facetas, 2003.Universidade

VANZELLA, Lila Cristina Guimarães. Projeto de Incentivo à leitura: uma experiência de pesquisa e formação. In: GOULART, Cecília M. A et al. A Alfabetização como processo discursivo. 30 anos de A criança na fase inicial da escrita. São Paulo: Cortez, 2017.

WALSH, Catherine. Lo pedagógico y lo decolonial: Entretejiendo caminhos. Colec vo Zapateándole al mal gobierno, 2014.

WILLIAMS, Raymond. Cultura. Rio de Janeiro: Paz e Terra, 2000. 239 p. 